\title{
Relationship between spine osteoarthritis, bone mineral density and bone turn over markers in post menopausal women
}

\author{
Linda Ichchou ${ }^{1 *}$, Fadoua Allali ${ }^{1,2}$, Samira Rostom¹, Loubna Bennani', Ihsane Hmamouchi ${ }^{1}$, Fatima Z Abourazzak', \\ Hamza Khazzani ${ }^{1}$, Laila El Mansouri ${ }^{1}$, Redouane Abouqal ${ }^{2}$, Najia Hajjaj-Hassouni ${ }^{1}{ }^{12}$
}

\begin{abstract}
Background: Several studies have observed an inverse relationship between osteoporosis and spinal osteoarthritis, the latter being considered as possibly delaying the development of osteoporosis. The aim of this study was to determine the association between individual radiographic features of spine degeneration, bone mineral density (BMD) and bone-turn over markers.

Methods: It was a cross sectional study of 277 post menopausal women. BMD of all patients was assessed at the spine and hip using dual-energy X-ray absorptiometry. Lateral spinal radiographs were evaluated for features of disc degeneration. Each vertebral level from L1/2 to L4/5 was assessed for the presence and severity of osteophytes and disc space narrowing (DSN). For Bone turn-over markers, we assessed serum osteocalcin and C-terminal cross-linking telopeptide of type I collagen (CTX). Linear regressions and partial correlation were used respectively to determine the association between each of disc degeneration features, BMD, and both CTX and osteocalcin.
\end{abstract}

Results: Mean age of patients was $58.7 \pm 7.7$ years. Eighty four patients (31.2\%) were osteoporotic and $88.44 \%$ had spine osteoarthritis. At all measured sites, there was an increase in BMD with increasing severity of disc narrowing while there was no association between severity of osteophytes and BMD. After adjustment for age and BMl, there was a significant negative correlation between CTX and DSN. However, no significant correlation was found between CTX and osteophytes and between osteocalcin and both osteophytes or DSN.

Conclusion: In post menopausal women the severity of disc narrowing, but not osteophytes, is associated with a generalized increase in BMD and a decreased rate of bone resorption. These results are consistent with the hypothesis that osteoarthritis, through DSN, has a protective effect against bone loss, mediated by a lower rate of bone resorption. However, spine BMD is not a relevant surrogate marker for the assessment of osteoporosis in the spine in patients with osteoarthritis and debate as to the relationship between OA and OP is still open because of the contradictory data in the literature.

\section{Background}

Osteoporosis (OP) and osteoarthritis (OA) are two common age-related skeletal disorders responsible for major health expenses in the elderly. While OA is a joint disease characterized by degeneration of articular cartilage and bone remodeling that may affect different sites and

\footnotetext{
* Correspondence: ilinda19@yahoo.fr

'Laboratory of Information and Research on Bone Diseases (LIRPOS). Department of Rheumatology, El Ayachi hospital, University Hospital of Rabat-Sale, Morocco

Full list of author information is available at the end of the article
}

involve peripheral or axial joints, OP is characterized by low bone mass, and microarchitectural deterioration of bony tissue, with a consequent increase in bone fragility and susceptibility to fractures. According to the WHO criteria, osteoporosis can also be defined as a value of bone mineral density (BMD) more than 2.5 standard deviations below the young normal mean.

It would be anticipated that osteoporosis and osteoarthritis frequently coexist due to their high prevalence in elderly women but the association between these 
conditions is still controversial $[1,2]$ even after years of research since the first results indicate an apparent inverse relationship $[3,4]$. Indeed, many studies have shown an association between high bone mineral density at the spine and hip and OA of the hips, knees or hands [5-8]. However, there are conflicting findings in the few published studies on the association between bone mass and degenerative disease in the spine, the latter being characterized by disc space narrowing (DSN) and the presence of vertebral osteophytes. Most [9-13], though not all [14-16] studies that examined the association between osteophytes and bone mass at the spine and distant sites including the hip, suggest that they are linked to an increased bone mass. Results are also discordant about the association between DSN and BMD at distant sites. In a population of patients with OA of the hip, isolated DSN without osteophytes was not associated with high bone mass [17]. In contrast, in a general population, those with isolated DSN have a higher BMD in the spine (but not in the hip) than those without [9].

In order to understand the underlying mechanism of the interaction between bone mass and OA, noninvasive biochemical assays for markers of bone resorption (which the CTX-I is the most specific and sensitive one), and bone formation have been developed and enabled estimation of bone turnover. Few studies of biochemical markers have been reported in subjects with spinal OA, results have also been conflictual [18-20].

We undertook this study to determine the association between radiographic features of lumbar disc degeneration, namely osteophytes and DSN, and BMD at different measured sites, as well as to investigate the underlying mechanism at the tissue level through assessment of biochemical markers of bone metabolism.

\section{Methods}

\section{Subjects}

The study involved 277 consecutive ambulatory postmenopausal women living in urban centre of Morocco and sent to our outpatient Bone Densitometry Center. Recruitment was based on voluntary enrolment. Written informed consent was obtained from all subjects and the study was approved by the Ethical Committee of El Ayachi University Hospital of Rabat-Sale. We excluded from the study all patients with a history of: (1) taking drugs known to influence bone metabolism in the past two years, such as vitamin D, calcium, corticosteroids, bisphosphonates, sodium fluoride, raloxifene, strontium ranelate, teriparatide and hormone replacement therapy; (2) musclo skeletal, thyroid, parathyroid, adrenal, hepatic, or renal disease; (3) malignancy; and (4) hysterectomy.

\section{Data collection and measurements}

Each patient completed a questionnaire on sociodemographic parameters and osteoporosis risk factors such as female sex, age higher than 60 years, family history of osteoporosis, early menopause, low BMI, smoking, sedentary lifestyle, long term ( $\geq 3$ months) corticosteroid use and excessive alcohol consumption. Weight and height were measured without clothes or shoes at the time of bone densitometry measurements. The body mass index (BMI) was calculated as body weight divided by height squared $\left(\mathrm{Kg} / \mathrm{m}^{2}\right)$.

\section{Bone mineral density (BMD) measurements}

Lumbar spine, trochanter, femoral neck and total hip BMD were measured by dual-energy X-ray absorptiometry with a Lunar prodigy densitometer. Only vertebras with scoliosis have been excluded from BMD test. Daily quality control was carried out by measurement of a Lunar phantom. At the time of the study, phantom measurements showed stable results. The in vivo precision error for dual-energy $\mathrm{X}$ ray absorptiometry, expressed as coefficient of variation, was $0.9 \%$ at the lumbar spine and $1 \%$ at the femoral neck. Both $\mathrm{T}$ and $\mathrm{Z}$ scores were obtained. In the T-score calculations, the manufacturer's ranges for European reference population were used because of the absence of a Moroccan data base.

\section{Assessment of lumbar spine degeneration}

Lumbar spine radiographs were taken according to a standard protocol with the film centred at L2 (Figure 1). The radiographs were subsequently evaluated by a single observer for the presence of the individual radiographic features of disc degeneration. Each vertebral level from L1/2 to L4/5 was assessed for the presence and severity of osteophytes and DSN, using a semiquantitative score (grade 0 , none; grade 1, mild; grade 2, moderate; grade 3 , severe) [21]. We defined, for each radiographic feature, two summary statistics: "MAX", which was the grade of the most severely affected vertebral level per subject (from L1/2 to L4/5) and which could range from 0 to 3, and "SUM", the sum of the four vertebral specific grades per subject which thus could range from 0 to 12 .

\section{Biochemical measurements}

Morning fasting blood was collected from every subject for the measurement of the following parameters: osteocalcin and C-terminal cross-linking telopeptide of type I (CTX). Both parameters were measured by immunochemoluminometric assay (Elecsys, Roche diagnostics, Mannheim, Germany). Intra- and interassay variances were $5 \%$ and $7 \%$, and the normal range were $15-46 \mathrm{ng} / \mathrm{ml}$ for osteocalcin, and $0.3-0.6 \mathrm{ng} / \mathrm{ml}$ for CTX. 


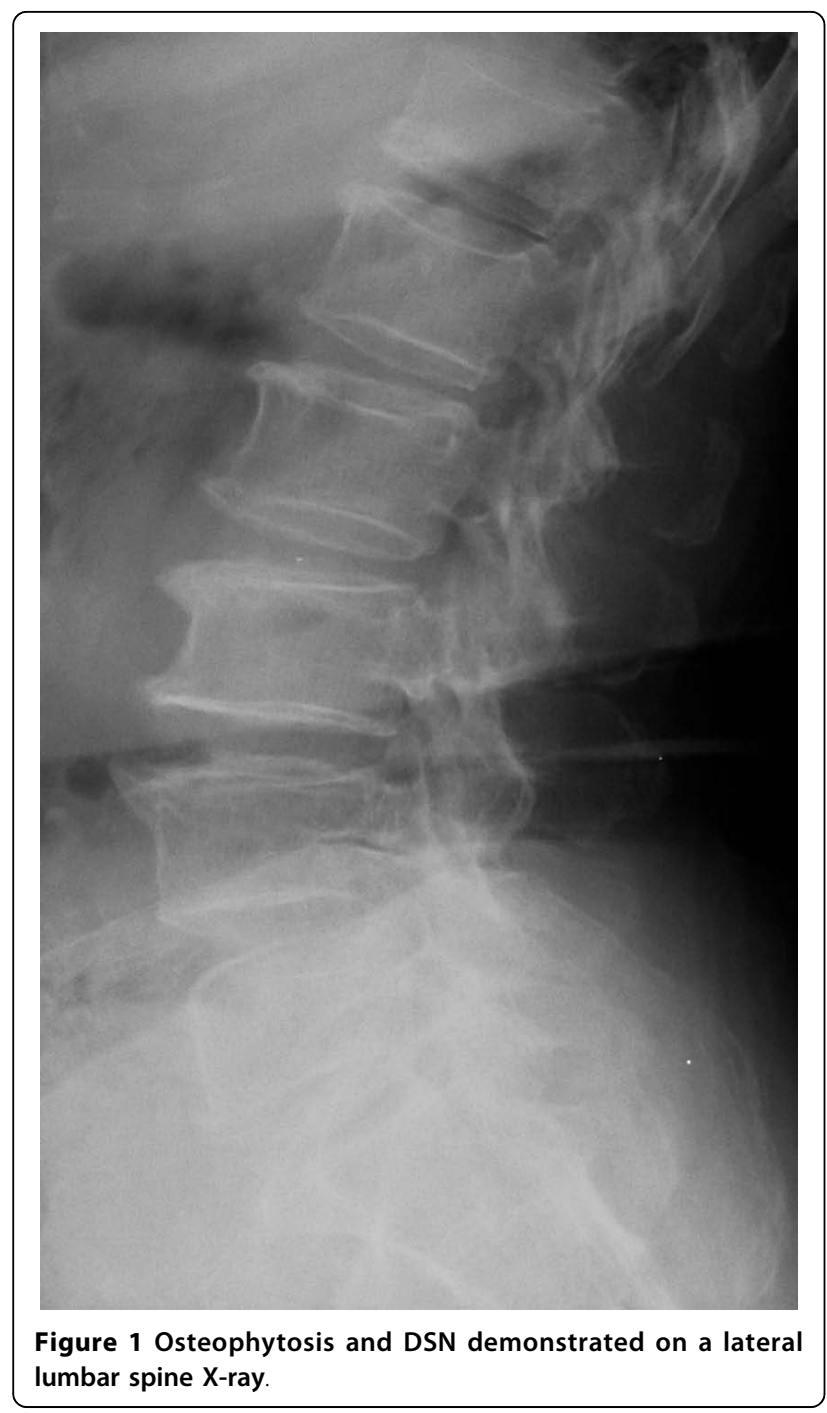

\section{Statistical analysis}

Statistical analysis was performed with SPSS for Windows 13.0 (SPSS Inc., Chicago, IL, USA). Population descriptions are expressed as mean \pm standard deviation (SD) for continuous variables and as percentage distributions for discrete variables.

Linear regression was used to determine the association between each of the two radiographic features (using both MAX and SUM) and BMD (dependent variable) at spine and femoral sites. Adjustments were made for age and BMI. We examined MAX as a continuous variable to test for any trend of increasing bone mass with increasing grade of radiographic feature. We examined SUM as a continuous variable to test for any trend of increasing bone mass with increasing grade of feature with the results expressed as $\beta$ coefficients and 95\% confidence intervals.
Partial correlation after adjusting for age and BMI was performed to determine the strength of the association between each of the radiographic features (using both MAX and SUM) and CTX and Osteocalcin. p values lower than 0.05 were considered as statistically significant.

\section{Results}

\section{Clinical characteristics}

Characteristics of participants enrolled in this cross sectional study are shown in table 1 . Mean age and BMI were $58.7 \pm 7.7$ years and $29.08 \pm 4.35 \mathrm{~kg} / \mathrm{m}^{2}$ respectively. 123 women $(44.4 \%)$ had overweight $(\mathrm{BMI}>25)$ and $101(36.5 \%)$ were obese. $88.44 \%$ of the 277 included in the study had spine osteoarthritis and $31.2 \%$ were osteoporotic. $43.5 \%$ had osteopenia, $46.6 \%$ of them had at least a prevalent vertebral fracture and $12.3 \%$ had a history of low trauma peripheral fractures. The prevalence of osteophytes and lumbar DSN was $87.5 \%$ and $47.2 \%$ respectively. Most of the patients $(78.8 \%)$ had a grade 1 of osteophytes. For DSN, 37.8\%, 7.2\% and 2.2\% of the patients had a grade 1,2 and 3 respectively. Mean level of CTX I and osteocalcin was $0.49 \pm 0.25$ and $24.56 \pm 13.56$ respectively.

\section{Maximum grade of radiographic feature (MAX) and BMD $\checkmark$ Lumbar spine BMD}

The association between BMD at the lumbar spine and the maximum grade of each radiographic feature per subject (MAX) is shown in table 2. After adjusting for age and BMI, lumbar spine BMD increased with

\section{Table 1 Subject characteristics}

\begin{tabular}{|c|c|}
\hline Variable & All subjects $(\mathrm{N}=277)$ \\
\hline & Mean $\pm S D$ \\
\hline Age (years) & $58.7 \pm 7.7$ \\
\hline Age of menopause (years) & $47.30 \pm 5.28$ \\
\hline Weight (kg) & $71.38 \pm 11.60$ \\
\hline Height (m) & $1,56 \pm 0,06$ \\
\hline $\mathrm{BMI}\left(\mathrm{Kg} / \mathrm{m}^{2}\right)$ & $29.08 \pm 4.35$ \\
\hline Lumbar spine BMD $\left(\mathrm{g} / \mathrm{cm}^{2}\right)$ & $0.966 \pm 0.159$ \\
\hline Femoral neck BMD $\left(\mathrm{g} / \mathrm{cm}^{2}\right)$ & $0.848 \pm 0.130$ \\
\hline Femoral trochanter BMD $\left(\mathrm{g} / \mathrm{cm}^{2}\right)$ & $0.693 \pm 0.120$ \\
\hline Total femoral BMD $\left(\mathrm{g} / \mathrm{cm}^{2}\right)$ & $0.892 \pm 0.134$ \\
\hline CTX I & $0.49 \pm 0.25$ \\
\hline \multirow[t]{2}{*}{ Osteocalcin } & $24.56 \pm 13.65$ \\
\hline & $\%$ \\
\hline Prevalence of osteoporosis & 31,2 \\
\hline Prevalence of spine osteoarthritis & 88.44 \\
\hline
\end{tabular}

BMD: bone mineral density

BMI: body mass index

DSN: disc space narrowing

CTX: C-terminal cross-linking telopeptide of type I collagen 
Table 2 Maximum grade (MAX) of individual radiographic features and BMD at different measured sites in 277 postmenopausal women

\begin{tabular}{|c|c|c|c|c|c|c|c|c|c|c|}
\hline & \multirow[b]{2}{*}{$\mathbf{n}$} & \multirow[b]{2}{*}{ (\%) } & \multicolumn{2}{|c|}{ Lumbar spine BMD } & \multicolumn{2}{|c|}{ Trochanter BMD } & \multicolumn{2}{|c|}{ Femoral neck BMD } & \multicolumn{2}{|c|}{ Femoral total BMD } \\
\hline & & & $\begin{array}{c}\text { Mean } \\
\text { (SD) }\end{array}$ & $\begin{array}{c}\text { Multivariate } \\
\text { analysis } \beta(95 \% \\
\text { Cl) }\end{array}$ & $\begin{array}{l}\text { Mean } \\
\text { (SD) }\end{array}$ & $\begin{array}{c}\text { Multivariate } \\
\text { analysis } \beta \text { (95\% } \\
\text { CI) }\end{array}$ & $\begin{array}{c}\text { Mean } \\
\text { (SD) }\end{array}$ & $\begin{array}{c}\text { Multivariate } \\
\text { analysis } \beta \text { (95\% } \\
\text { CI) }\end{array}$ & $\begin{array}{l}\text { Mean } \\
\text { (SD) }\end{array}$ & $\begin{array}{c}\text { Multivariate } \\
\text { analysis } \beta \text { (95\% } \\
\text { CI) }\end{array}$ \\
\hline \multicolumn{11}{|c|}{ Osteophytes } \\
\hline Grade 0 & 34 & $(12.5)$ & $\begin{array}{c}0.983 \\
(0.187)\end{array}$ & 1 & $\begin{array}{c}0.710 \\
(0.125)\end{array}$ & 1 & $\begin{array}{c}0.884 \\
(0.125)\end{array}$ & 1 & $\begin{array}{c}0.925 \\
(0.149)\end{array}$ & 1 \\
\hline Grade 1 & 219 & $(78.8)$ & $\begin{array}{c}0.963 \\
(0.153)\end{array}$ & $-0.01(-0.05$ to 0.05$)$ & $\begin{array}{c}0.693 \\
(0.121)\end{array}$ & $-0.01(-0.04$ to 0.03$)$ & $\begin{array}{c}0.845 \\
(0.134)\end{array}$ & $-0.02(-0.07$ to 0.02$)$ & $\begin{array}{c}0.889 \\
(0.132)\end{array}$ & $-0.01(-0.01$ to 0.02$)$ \\
\hline Grade 2 & 11 & $(4.0)$ & $\begin{array}{c}0.937 \\
(0.217)\end{array}$ & 0.02 (-0.07 to 0.13$)$ & $\begin{array}{c}0.643 \\
(0.103)\end{array}$ & $-0.01(-0.08$ to 0.06$)$ & $\begin{array}{c}0.822 \\
(0.884)\end{array}$ & $-0.01(-0.08$ to 0.08$)$ & $\begin{array}{c}0.849 \\
(0.110)\end{array}$ & 0.01 (-0.07 to 0.08$)$ \\
\hline Grade 3 & 13 & $(4.7)$ & $\begin{array}{c}0.989 \\
(0.140)\end{array}$ & $-0.01(-0.08$ to 0.06$)$ & $\begin{array}{c}0.693 \\
(0.120)\end{array}$ & $-0.01(-0.08$ to 0.06$)$ & $\begin{array}{c}0.831 \\
(0.992)\end{array}$ & $-0.03(-0.11$ to 0.04$)$ & $\begin{array}{c}0.891 \\
(0.128)\end{array}$ & $-0.01(-0.08$ to 0.06$)$ \\
\hline \multicolumn{11}{|l|}{ DSN } \\
\hline Grade 0 & 146 & $(52.8)$ & $\begin{array}{c}0.953 \\
(0.156)\end{array}$ & 1 & $\begin{array}{c}0.686 \\
(0.121)\end{array}$ & 1 & $\begin{array}{c}0.845 \\
(0.144)\end{array}$ & 1 & $\begin{array}{c}0.896 \\
(0.137)\end{array}$ & 1 \\
\hline Grade 1 & 105 & (37.8) & $\begin{array}{c}0.974 \\
(0.255)\end{array}$ & $0.02(-0.01$ to 0.06$)$ & $\begin{array}{c}0.674 \\
(0.114)\end{array}$ & $0.01(-0.01$ to 0.04$)$ & $\begin{array}{c}0.849 \\
(0.110)\end{array}$ & $0.01(-0.02$ to 0.04$)$ & $\begin{array}{c}0.885 \\
(0.130)\end{array}$ & $-0.01(-0.03$ to 0.02$)$ \\
\hline Grade 2 & 20 & $(7.2)$ & $\begin{array}{c}0.966 \\
(0.232)\end{array}$ & $0.07(-0.01 \text { to } 0.14)^{*}$ & $\begin{array}{c}0.689 \\
(0.152)\end{array}$ & $0.05(-0.01 \text { to } 0.10)^{*}$ & $\begin{array}{c}0.870 \\
(0.137)\end{array}$ & $0.08(0.02 \text { to } 0.14)^{*}$ & $\begin{array}{c}0.893 \\
(0.146)\end{array}$ & $0.06(0.01 \text { to } 0.12)^{*}$ \\
\hline Grade 3 & 6 & $(2.2)$ & $\begin{array}{c}1.118 \\
(0.861)\end{array}$ & $0.19(0.07 \text { to } 0.30)^{*}$ & $\begin{array}{c}0.683 \\
(0.120)\end{array}$ & $0.01(-0.06$ to 0.10$)$ & $\begin{array}{c}0.843 \\
(0.931)\end{array}$ & $0.02(-0.07$ to 0.12$)$ & $\begin{array}{c}0.909 \\
(0.107)\end{array}$ & $0.05(-0.04$ to 0.14$)$ \\
\hline
\end{tabular}

${ }^{*} p<0.05$

Adjustment for age and BMI in the multivariate analysis

BMD: bone mineral density

increasing grade of disc space narrowing. For example, the mean age-adjusted lumbar spine BMD rises from $0.95 \mathrm{~g} / \mathrm{cm}^{2}$ for patients without DSN to $1.118 \mathrm{~g} / \mathrm{cm}^{2}$ for patients with grade 3 of DSN ( $p=0.001)$. This trend of increasing BMD with increasing grade of DSN persisted after adjusting for BMI. However, there was no association between lumbar spine BMD and osteophytes.

\section{$\checkmark$ Femoral BMD}

The association between the MAX of each radiographic features and BMD at the neck, tochanter, and total femoral is shown in table 2. After adjusting for age, patients with grade 2 of DSN had an increased BMD at all measured sites than other patients. For example, the mean age-adjusted femoral neck BMD was $0.845 \mathrm{~g} / \mathrm{cm}^{2}$ for patients without DSN and $0.870 \mathrm{~g} / \mathrm{cm}^{2}$ for patients with grade 2 of DSN ( $\mathrm{p}=0.003$ ). This trend of increasing BMD in patients with grade 2 of DSN persisted after adjusting for BMI. In contrast, there was no association between femoral BMD and osteophytes.

\section{Summary score for radiographic features (SUM) and BMD}

The influence of the radiographic features as assessed using the total score (SUM) across all the four intervertebral levels, on BMD at all measured sites, is shown in table 3. Results are expressed as $\beta$ coefficients which may be interpreted as the absolute change in BMD $\left(\mathrm{g} / \mathrm{cm}^{2}\right)$ per unit change in score. BMD at all measured sites increased with SUM DSN. For example, after age adjustment, lumbar BMD increased by a value of $0.02 \mathrm{~g} / \mathrm{cm}^{2}$ for each unit change in the total DSN score. The observed associations remain unchanged after adjustment for age and BMI. However, there was no association between BMD at all measured sites and SUM osteophytes.

\section{Relationship between osteoarthritis and bone turn over markers}

A significant decrease in CTX-I levels associated with lumbar spine disc degeneration was observed (table 4). Indeed, after adjustment for age and BMI there was a significant negative correlation between CTX and MAX DSN ( $r$ adjusted $=-0.192, p=0.026$ ). The level of CTX was also negatively associated with SUM DSN ( $\mathrm{r}$ adjusted $=-0.209, \mathrm{p}=0.019)$. However, no significant correlation was found between CTX and MAX or SUM osteophytes and between osteocalcin; and both SUM and MAX DSN or osteophytes.

\section{Discussion}

Our data show that in post menopausal women increasing severity of disc space narrowing, but not osteophytes, is related to increasing bone mineral density at all measured sites. The severity of disc space narrowing 
Table 3 Total scores (SUM) of individual radiographic features and BMD at different measured sites, after adjusting for age and BMI, in 277 postmenopausal women

\begin{tabular}{lcccc}
\hline & $\begin{array}{c}\text { Lumb spine BMD } \\
\boldsymbol{\beta}(\mathbf{9 5 \%} \mathrm{Cl})\end{array}$ & $\begin{array}{c}\text { Trochanter BMD } \\
\boldsymbol{\beta} \text { (95\% Cl) }\end{array}$ & $\begin{array}{c}\text { Femoral neck BMD } \\
\boldsymbol{\beta} \text { (95\% Cl) }\end{array}$ & $\begin{array}{c}\text { Total femoral BMD } \\
\boldsymbol{\beta}(\mathbf{9 5} \% \mathrm{Cl})\end{array}$ \\
\hline Osteophyte & $-0.01(-0.01$ to 0.01$)$ & $-0.01(-0.01$ to 0.01$)$ & $-0.01(-0.01$ to 0.01$)$ & $-0.01(-0.01$ to 0.01$)$ \\
DSN & $0.02(0.01 \text { to } 0.03)^{*}$ & $0.01(0.01 \text { to } 0.02)^{*}$ & $0.01(0.01 \text { to } 0.02)^{*}$ & $0.01(0.01 \text { to } 0.02)^{*}$ \\
\hline
\end{tabular}

${ }^{*} p<0.05$

BMD: bone mineral density

DSN: disc space narrowing

$\mathrm{Cl}$ : confidence interval

was also associated to a decrease in bone resorption, without any effect on bone formation.

Marked differences in the prevalence of spinal degeneration features occur in association with older age, female sex, post menopausal women and obesity. In our study, the prevalence of spine osteoarthritis was high (88.44\%). $78.7 \%$ and $47.7 \%$ of patients had at least one osteophyte or at least one DSN respectively. This can be explained by age (Mean (SD) age was $58.7 \pm 7.7$ ), sex, overweight $(44.4 \%$ had BMI $>25)$ and obesity $(36.5 \%$ of the patients). Mean (SD) BMI was $29.08 \pm 4.35$.

On the other hand, several studies observe an inverse relationship between $\mathrm{OP}$ and spine $\mathrm{OA}$, the latter being considered as possibly delaying the development of OP $[10,18,19,21]$. Our data showed that increasing BMD in spine OA is more related to DSN than to osteophytes. Indeed, after adjusting for age and BMI, no association was found between BMD at all measured sites and the severity of osteophytes. This can be explained by the fact that the majority of the patients $(78.8 \%)$ had only a grade 1 of osteophytes which corresponds to a mild involvement of this radiographic feature. The influence of osteophytes on BMD has been the focus of various studies, which showed, in contrast to our findings $[6,10,12,16-18]$, that spinal BMD was greater in vertebrae with osteophytes. Several other studies have examined the association between osteophytes and bone mass at distant sites including the hip and most $[6,9-13,18]$, though not all [14-16] suggest that they are also linked to an increased bone mass. However, it is important to

Table 4 Partial Correlation showing a significant negative correlation between CTX and DSN in 277 postmenopausal women

\begin{tabular}{lcc}
\hline & CTX r adjusted & Osteocalcin r adjusted \\
\hline MAX osteophyte & -0.097 & -0.032 \\
SUM osteophyte & -0.137 & -0.135 \\
MAX DSN & $-0.192^{*}$ & -0.036 \\
SUM DSN & $-0.209^{*}$ & -0.075 \\
\hline
\end{tabular}

${ }^{*} p<0.05$

Adjustement for age and BMI

CTX: C-terminal cross-linking telopeptide of type I collagen

DSN: disc space narrowing note that spine disc degeneration can hinder the interpretation of spine BMD: osteophytes cannot be distinguished from vertebral bone mineral using BMD area measurements and may even in some cases overestimate the measurements of bone mass in the affected areas. Therefore, it has been suggested that spine BMD is not a relevant surrogate marker for the assessment of osteoporosis in the spine in patients with osteoarthritis $[9,12]$.

Relatively little however is known about the association between bone mass and DSN and there are also conflicting findings in the few published studies on the subject $[12-14,16,17]$. Thus, in a population of patients with OA of the hip, isolated DSN without osteophytes was not associated with high bone mass [17]. In contrast, Pye et al showed an association between DSN and increasing BMD at the spine but not at the hip [9]. Our data show that increasing severity of DSN is associated with increasing BMD at all measured sites and support, through the DSN results, the hypothesis that degenerative disc disease is inversely linked with osteoporosis.

The mechanism is unknown though several are possible; including confounding by environmental or constitutional factors, hormonal, metabolic, and genetic factors $[22,23]$. Our results remained unchanged after adjustment for age and BMI, suggesting that they do not play a major role in explaining the observed associations.

Few studies of biochemical markers have been reported in subjects with spinal OA, with discordant results [18-20]. Peel et al [18] and El Miedany et al [19] have shown that spinal OA is associated with a generalized increase in BMD and decreased levels of serum and urinary biochemical markers of bone formation and bone resorption in patients with spine disc degeneration. It has been suggested that the protective effect of spinal OA against OP may be mediated through decreased rate of bone turnover. Garnero et al [20] in a large cohort of untreated postmenopausal women participating in the OFELY prospective study have shown recently that lumbar spine DSN, but not osteophytes, is strongly associated with increased CTX-II degradation, independently of age and BMI. Our results agree partially with what has been reported by Peel et al. and El Miedany et al $[18,19]$ who found in their studies a decrease in bone 
resorption markers in women with spinal OA. However, we did not find any effect of spine disc degeneration on bone formation. Moreover, no association was found between the severity of osteophytes and either increasing BMD or CTX levels.

Our study is limited by its cross-sectional design and the use of a semiquantitative score to classify the radiographic features of disc degeneration. As with any subjective evaluation, this is subject to errors of interpretation which may result in misclassification. However, this defect applies to all studies in this field because the same grading systems are used universally. Moreover, only 9.4\% of our subjects had disc space narrowing that was associated with a significantly increased bone mineral density and further studies on a larger population are necessary to confirm our findings. Finally, and as mentioned above, spine BMD is not a relevant surrogate marker for the assessment of osteoporosis in the spine in patients with osteoarthritis. Indeed, measurements of BMD taken by DXA are the most accurate procedure for the diagnosis of osteoporosis nowadays. However, these measurements are two-dimensional and when made with an anterior-posterior projection, the most used incidence, this procedure has the disadvantage of measuring the density of all the mineral components encountered in the $\mathrm{X}$-ray pathway, including osteophytes, bone sclerosis, disk space narrowing, spondylolisthesis, vertebral fractures, and vascular and extra-vertebral calcifications. Moreover, some studies has actually shown that obesity and these alterations can influence bone mineral density results. Although this defect applies to all studies in this field because DXA is used universally, it would be interesting to study OA in other places.

\section{Conclusion}

This study showed that in post menopausal women the severity of disc narrowing, but not osteophytes, was associated with a generalized increase in BMD and a decreased rate of bone resorption. These results are consistent with the hypothesis that osteoarthritis, through disc space narrowing, has a protective effect against bone loss, mediated by a lower rate of bone resorption. However, spine BMD is not a relevant surrogate marker for the assessment of osteoporosis in the spine in patients with osteoarthritis and debate as to the relationship between OA and OP is still open because of the contradictory data in the literature.

\footnotetext{
Acknowledgements

This work was supported by grants from the University Mohammed V, Souissi, Rabat-Morocco.

The University Hospital Center of Rabat-Morocco supported the bone mineral density measures.
}

\section{Author details}

${ }^{1}$ Laboratory of Information and Research on Bone Diseases (LIRPOS). Department of Rheumatology, El Ayachi hospital, University Hospital of Rabat-Sale, Morocco. ${ }^{2}$ Laboratory of Biostatistical, Clinical and Epidemiological Research (LBRCE). Faculty of Medicine and Pharmacy, Rabat, Morocco.

\section{Authors' contributions}

$\mathrm{LI}$ participated in study design and drafted the manuscript. FA conceived the original idea for the study, supervised its design, performed the statistical analysis and gave critical comments on the draft manuscript. SR enrolled patients, participated in data acquisition and critical revision of the manuscript. LB enrolled patients, participated in data acquisition and critical revision of the manuscript. $\mathrm{IH}$ enrolled patients, participated in data acquisition and critical revision of the manuscript. FZA enrolled patients, participated in data acquisition and critical revision of the manuscript. HK enrolled patients, participated in data acquisition and critical revision of the manuscript. LE enrolled patients, participated in data acquisition and critical revision of the manuscript. RA conceived the study and performed the statistical analysis. $\mathrm{NHH}$ participated in the study design, coordinated the study and gave critical comments on the draft manuscript. All authors read and approved the final manuscript.

\section{Competing interests}

The authors declare that they have no competing interests.

Received: 6 February 2010 Accepted: 8 August 2010

Published: 8 August 2010

\section{References}

1. Dequeker J, Aerssens J, Luyten FP: Osteoarthritis and osteoporosis: clinical and research evidence of inverse relationship. Aging Clin Exp Res 2004, 15:426-39.

2. Sambrook $P$, Naganathan $V$ : What is the relationship between osteoarthritis and osteoporosis? Baillieres Clin Rheumatol 1997, 11:695-710.

3. Foss MVL, Byers PD: Bone density, osteoarthritis of the hip, and fracture of the upper end of the femur. Ann Rheum Dis 1972, 31:259-64.

4. Roh YS, Dequeker J, Mulier JC: Cortical bone remodeling and bone mass in primary osteoarthritis of the hip. Invest Radiol 1973, 8:251-4.

5. Gevers G, Dequeker J, Geusens P: Physical and histomorphological characteristics of iliac crest bone differ according to the grade of osteoarthritis at the hand. Bone 1989, 10:173-7.

6. Reid IR, Evans MC, Ames R, Wattie DJ: The influence of osteophytes and aortic calcification on spinal mineral density in postmenopausal women. J Clin Endocrinol Metab 1991, 72:1372-6.

7. Äström J, Beertema J: Reduced risk of hip fractures in the mothers of patients with osteoarthritis of the hip. J Bone Joint Surg Br 1992, 74:270-5.

8. Hannan MT, Anderson JJ, Zhang Y: Bone mineral density and knee osteoarthritis in elderly men and women. The Framingham Study. Arthritis Rheum 1993, 36:1671-6.

9. Pye SR, Reid DM, Adams JE, Silman AJ, O'Neill TW: Radiographic features of lumbar disc degeneration and bone mineral density in men and women. Ann Rheum Dis 2006, 65:234-8.

10. Masud T, Langley S, Wiltshire P, Doyle DV, Spector TD: Effect of spinal osteophytosis on bone mineral density measurements in vertebral osteoporosis. BMJ 1993, 307:172-3.

11. Hart DJ, Mootoosamy I, Doyle DV, Spector TD: The relationship between osteoarthritis and osteoporosis in the general population: the Chingford Study. Ann Rheum Dis 1994, 53:158-62.

12. Jones G, Nguyen T, Sambrook PN, Kelly PJ, Eisman JA: A longitudinal study of the effect of spinal degenerative disease on bone density in the elderly. J Rheumatol 1995, 22:932-6.

13. Miyakoshi N, Itoi E, Murai H, Wakabayashi I, Ito H, Minato T: Inverse relation between osteoporosis and spondylosis in postmenopausal women as evaluated by bone mineral density and semiquantitative scoring of spinal degeneration. Spine 2003, 28:492-5.

14. Liu G, Peacock M, Eilam O, Dorulla G, Braunstein E, Johnston CC: Effect of osteoarthritis in the lumbar spine and hip on bone mineral density and diagnosis of osteoporosis in elderly men and women. Osteoporos Int 1997, 7:564-9. 
15. Dalle Carbonare L, Giannini S, Sartori L, Nobile M, Ciuffreda M, Silva-Netto F, Arlot ME, Crepaldi G: Lumbar osteoarthritis, bone mineral density, and quantitative ultrasound. Aging (Milan) 2000, 12:360-5.

16. Muraki $S$, Yamamoto $S$, Ishibashi $H$, Horiuchi T, Hosoi T, Orimo $H_{\text {, }}$ Nakamura K: Impact of degenerative spinal diseases on bone mineral density of the lumbar spine in elderly women. Osteoporos Int 2004, 15:724-8.

17. Nevitt MC, Lane NE, Scott JC, Hochberg MC, Pressman AR, Genant HK, Cummings SR: Radiographic osteoarthritis of the hip and bone mineral density. The Study of Osteoporotic Fractures Research Group. Arthritis Rheum 1995, 38:907-16.

18. Peel NF, Barrington NA, Blumsohn A, Colwell A, Hannon R, Eastell R: Bone mineral density and bone turnover in spinal osteoarthrosis. Ann Rheum Dis 1995, 54:867-71.

19. El Miedany YM, Mehanna AN, El Baddini MA: Altered bone mineral metabolism in patients with osteoarthritis. Joint Bone Spine 2000, 67:900-7.

20. Garnero P, Sornay-Rendu E, Arlot M, Christiansen C, Delmas PD: Association between Spine Disc Degeneration and Type II Collagen Degradation in Postmenopausal Women, The OFELY Study. Arthritis Rheum 2004, 50:3137-44.

21. Verstraeten A, Ermen HV, Haghebaert G, Nijs J, Geusens P, Dequeker J: Osteoarthritis retards the development of osteoporosis: observation of the coexistence of osteoarthritis and osteoporosis. Clin Orthop 1991, 264:169-77.

22. Dequeker J, Mohan S, Finkelman RD, Aerssens J, Baylink DJ: Generalised osteoarthritis associated with increased insulin-like growth factors types I and II and transforming growth factor $\mathrm{b}$ in cortical bone from the iliac crest. Arthritis Rheum 1993, 36:1702-8.

23. Holderbaum D, Haqqi TM, Moskowitz RW: Genetics and osteoarthritis: exposing the iceberg. Arthritis Rheum 1999, 42:397-405.

\section{Pre-publication history}

The pre-publication history for this paper can be accessed here: http://www.biomedcentral.com/1472-6874/10/25/prepub

\section{doi:10.1186/1472-6874-10-25}

Cite this article as: Ichchou et al:: Relationship between spine osteoarthritis, bone mineral density and bone turn over markers in post menopausal women. BMC Women's Health 2010 10:25.

\section{Submit your next manuscript to BioMed Central and take full advantage of:}

- Convenient online submission

- Thorough peer review

- No space constraints or color figure charges

- Immediate publication on acceptance

- Inclusion in PubMed, CAS, Scopus and Google Scholar

- Research which is freely available for redistribution

Submit your manuscript at www.biomedcentral.com/submit
Biomed Central 